\title{
Analysis of world practices for stimulating the development of renewable energy sources. A case study for Russian conditions
}

\author{
Dmitriy N. Karamov ${ }^{12}$, Ilia A. Maltsev ${ }^{1}$, Bain B. Tsyrendorzhiev ${ }^{1}$ \\ ${ }^{1}$ Melentiev Energy Systems Institute of Siberian Branch of the Russian Academy of Sciences, Irkutsk \\ ${ }^{2}$ Irkutsk National Research Technical University, Irkutsk
}

\begin{abstract}
This document analysis the methods of stimulating renewable energy (RES) in various countries, describes the barriers and problems that hinder the development of alternative energy. Studies conducted in countries with a developed renewable energy sector will allow us to conclude that the development incentive systems (Feed-in-tariff (FIT), Renewable Energy Portfolio Standard (RSP), auctions, reverse auctions and various tax incentives) have had the required impact and the government of such countries has moved to establish parity between renewable and traditional energy, as well as to optimize the systems for promoting the development of clean energy. Green energy in countries that are actively developing renewable energy are building models and infrastructures based on the experience and methods of solving the problems of countries with a developed RES support system.
\end{abstract}

Key words: renewable energy source, feed-in-tariff, renewable energy portfolio standard, auctions, reverse auctions, green certificates

\section{Introduction}

The modern vector of the world's energy policy is aimed at increasing the share of RES in the total generation of different countries. The accelerated transition to carbon-free energy is dictated by the current situation in the global energy market for raw materials, as well as the signing of the historic "Paris Agreement" on the climate, which implies a reduction in greenhouse gas emissions into the atmosphere. The Kyoto Protocol and twenty years later the Paris Agreement are fundamental mechanisms for the transition to clean energy around the world.

The transformation of energy systems towards clean energy sources required an improvement in the regulatory framework. The development of mechanisms to support RES has contributed to the sustainable growth of installed capacities of photovoltaic systems and wind farms.

The purpose of this article is to provide a detailed overview of the existing global trends in RES development (Section 2), as well as the achievements of the Russian government in the field of green energy development (Section 3). Section 4 includes a summary of the analysis.

\footnotetext{
*Corresponding author: dmitriy.karamov@mail.ru
}

\section{World Experience}

This section provides the experience of developed countries in the field of stimulating the development of RES, problems and possible solutions, as well as the experience of countries at the initial stage of development in this direction. The research is based on the analysis of scientific publications by various authors.

\subsection{Asia}

\subsubsection{Japan}

The article [1] raises the problem of the relationship between producers in Japan who do not use RES and those who use. Renewable energy producers form their activities based on the price set by the government and the margin required for profitability. And they also have the opportunity to receive additional profit through the sale of "green certificates" (this is a document that allows you to confirm the purchase of electricity from RES) thanks to the RSP scheme (RSP - a system in which the State obliges companies to acquire green certificates for a certain amount of electricity from energy generating companies working with renewable energy). With this support, renewable energy producers have good potential 
for development. However, due to the increase in the volume of RES in the electricity market, producers of non-renewable energy suffer from reduced income. Also, the maintenance of the network and modernization for the new load from renewable energy lies with the producers of non-renewable energy. On the other hand, renewable energy producers require a special approach to integrate into the grid, since the generation of electricity in their case is not constant. Therefore, in this situation, producers of non-renewable energy use their dominant position in the market and oppose the active integration of renewable energy producers into the power grid. In this situation, the Japanese government needs to solve a number of problems, such as modernizing and strengthening the electrical network in the most cost-effective way.

\subsubsection{China}

In 2011, China ranked first among the world's wind power producers. Since the end of the last century, aggregate wind energy production has grown from 1 billion GW to 150 billion $\mathrm{GW}$ in 2017. The average annual growth rate was almost $50 \%$. This progress was made possible thanks to the artificially high FIT rate by the Chinese government. The high profitability of wind systems due to the FIT rate, as well as the country's general policy aimed at the early development of renewable energy, made it possible to create attractiveness for investors, which in turn reinforced the pace of increasing wind power generation capacity.

However, excessive subsidies, which gave rise to a high rate of development of wind systems, created a number of problems, which are described in detail in the article [2]. One of the key challenges is the reduction in wind power supply. The lack of methods for transporting and distributing energy throughout the country as a result of the disproportionately high cost of building energy distribution systems creates idle capacity in wind power plants. Regions of the country that have not been able to provide access to energy from wind systems are forced to use traditional electricity production from fossil fuels. The article cites data that between 2009 and 2017, 190 billion $\mathrm{kWh}$ were reduced, this is $15 \%$ of total wind generation, 61 million tons of coal for energy production or 170 million tons of $\mathrm{CO}^{2}$ emissions that could have been avoided. In the long term, these data can affect the attractiveness of projects for investors, as well as affect the calculated policy of the industry development.

This problem can be solved by changing the attitude to the regulation of the FIT rate. Too slow regulation causes excessive investment in energy production systems, and as a result, energy transportation systems around the country do not cope with production capabilities. This article provides a theoretical model of a more subtle and intensive regulation of the FIT rate at the provincial level, as a result of the assessment of which it was found that with an increase in the tariff by 0.1 yuan, the rate of cutting the capacity of wind systems would increase by $2-3 \%$. An increase in the frequency of changes in the FIT rate, according to the favorable scenario of the model, would reduce the reduction in energy production

\section{by $23-27$ billion $\mathrm{kWh}$.}

The Chinese government is setting ambitious plans for the development of RES, FIT is one of the most important keys to regulate the development of environmentally friendly energy. And also, the issue of the timely development of infrastructure for the transportation and distribution of energy throughout the country takes a priority place in the planning by the Chinese government of a strategy for the development of energy production at the expense of RES. Thanks to the Action Plan on Green Energy Consumption 2018-2020, which was adopted in 2018 , the government was able to reduce the reduction in energy production from $15 \%$ to $8 \%$.

Also, worth noting is an interesting project described in article [3]. This article describes a hybridization project for coal-fired power plants with solar power plants. A key factor in attracting investment in this project is the use of FIT as a government subsidy. According to calculations, the state should set the FIT at 1.21 yuan / $\mathrm{kWh}$ in order to offset inflation at around $8 \%$ and ensure the project is profitable for investors.

\subsubsection{South Korea}

The South Korean government uses the RSP system as the main principle to stimulate the development of RES. Since this incentive has a number of disadvantages, for example, a high price risk for small industries, the South Korean government has supplemented its policy of incentives with auctions for small industries. The pros and cons of the simultaneous use of different incentives, as well as the existing experience in the field of renewable energy in the country are described in article [4]. The author of the article [4] emphasizes that the simultaneous use of different incentives will allow the selection of more appropriate methods of support for different types of RES. Thanks to the introduction of auctions (described in more detail in the South America section) for long-term contracts for the supply of energy from renewable sources in 2017, a drop in spot prices for green certificates was achieved by increasing the number of small and mediumsized photovoltaic systems. The additional introduction of FIT for small solar power suppliers in 2018 reduced the prices of green certificates again. Excessively rapid price reductions can affect the attractiveness of small green energy systems. The problem of an excessive reduction in the price of energy will have an impact in the long term, and in order to solve it, it is necessary to build a balance from the very early stage of the simultaneous use of different incentives for the development of RES.

The main purpose of this article is to draw attention to the need to create an infrastructure for monitoring the interaction of various incentives, as well as to the problem of an oversupply of energy on the market, followed by an excessive drop in prices. The experience of South Korea in using various incentives is evaluated in [4] as successful and will allow other countries to gain an understanding of the potential problems in organizing such a system for stimulating the development of RES. 


\subsubsection{Saudi Arabia}

The demand for electricity in Saudi Arabia is increasing every year. Electricity consumption in this country has been growing by about $7-8 \%$ annually over the past ten years, and demand in the summer period of the year, increased by $93 \%$ from 2004-2013, consumption increased from 28 to $54 \mathrm{GW}$. By 2032, with a constantly growing demand for consumption, it is predicted that electricity generation will increase to $120 \mathrm{GW}$ [5]. So, for example, the article describes [6] the solution to this problem. Since 2018, Saudi Arabia has begun to develop a project for generating electricity using solar power plants with a total capacity of 150-200 GW. In addition to meeting electricity demand, the project allows homeowners to install and integrate solar photovoltaic systems (RSPS) into the utility grid in their homes. It should also be noted that Saudi Arabia has launched a large-scale plan Saudi Vision 2030. Its main task is to reduce the country's dependence and diversify the economy from oil, as well as to help replace it with RES [6]. As again mentioned in [5], according to a survey of the population, the majority of respondents $(79.7 \%)$ are ready to purchase RSPS, provided that they could receive subsidies from the authorities equivalent to $40 \%$ of the initial cost.

In the article [6], the advantages and problems associated with the adoption of a preferential rate policy in Saudi Arabia are considered. As such, there is practically no FIT policy in the country, the main goal of the article was how to find a possible application of FIT in the RES in Saudi Arabia by revising the FIT rates in Germany and the USA (California) (by simulating the generation and consumption of electricity in the private sector using a $10 \mathrm{~kW}$ photovoltaic system over 25 years, based on the current FIT policies in these countries) and already based on this method, determines the most suitable FIT rate in Saudi Arabia for different regions in terms of investment, electricity consumption of the same private sector, compatibility with the existing network, the period required for the return of assets and long-term beneficial benefits. Based on the results obtained, the author concludes that the FIT rate is $0.08 \mathrm{SAR} / \mathrm{kWh}$. The payback period for investment and maintenance of the system is 7-8 years for all regions, with the exception of the south, where 8-9 years, respectively. Due to the increase in electricity tariffs at the beginning of 2018 to $0.18 \mathrm{SAR} / \mathrm{kWh}$ (which is almost 3 times more than it was), the rate of return on investment is slow and not profitable enough to attract agents. In order for Saudi Arabia to start using the sun as a RES, it will be necessary to raise the FIT rate to $0.12 \mathrm{SAR} / \mathrm{kWh}$ at the current electricity tariff $(0.18 \mathrm{SAR} / \mathrm{kWh})$, in order to ensure an acceptable payback for a photovoltaic installation within 5 years.

\subsection{Europe}

\subsubsection{Germany}

In Germany, the gross electricity production from renewable sources was $33 \%$ in 2017 . The basis for this figure was a policy to stimulate the development of renewables by introducing feed-in tariffs since 1991 . Following the German government's decision to shift the cost of grid modernization from renewable energy developers to grid operators, feed-in tariffs have become more attractive for investment. The [7] describes the impact of changes in the feed-in tariff on overall wind power generation as well as emissions reductions due to reduced load on solid-fuel power plants. Compared to other incentives to reduce harmful emissions, the feed-in tariff has an impact of $4 \%$ lower costs and is most attractive to investors, especially in wind power. The German government guarantees access to the transmission grid for renewable energy producers, so organizing energy production by wind systems in areas of high wind activity in Germany is seen as extremely promising by investors.

The mentioned article provides data on the impact of the feed-in tariff rate on the overall national level of wind power generation. An increase of $1 \mathrm{cent} / \mathrm{kW}$ would result in an increase of $905 \mathrm{MW}$ per year in national added capacity between 2000 and 2010. This data confirms a high prospect for renewable energy in Germany and the presence of a qualitative producer response to such an incentive as a feed-in tariff. Germany is one of the leaders in green energy development. Most of the projects of other countries to use the green tariff scheme is based on the experience of Germany, looking at the policy of development of renewable energy sources, as well as reducing harmful emissions from producers of conventional energy, by reducing the burden.

\subsubsection{United Kingdom (UK)}

In recent years, the UK has successfully subsidized the development of renewable energy sources through a high green tariff rate, sources such as photovoltaic systems in households have been very successful in contributing to the country's environmental goals. However, to settle the parity of electricity sources in the grid, the U.K. government needs to lower the green tariff rate. Based on the data cited in the article [8], it can be concluded that in the UK there are discussions between regulators, utilities and solar companies about the possible effects of green tariff rate cuts. The green rate reduction is justified by the government as a way to settle parity of electricity generation between renewable and non-renewable companies. One of the most important consequences of the reduction of green tariff rates is the change in the priority of giving energy to the grid for self-consumption. It arises from the profitability of renewable energy production, with a lower feed-in tariff rate, it becomes more profitable for producers to partially supply themselves with energy and save money than to supply surplus energy to the grid. In addition, lower grid energy will result in higher electricity prices, reinforcing the desire to stop supplying surplus energy to the grid, and to benefit by providing their own electricity consumption from renewable sources.

One of the biggest model for renewable energy 
sources in the UK is photovoltaic modules. When the profitability of electricity production shifts toward personal use instead of giving the surplus to the grid, there will be a pattern of using batteries to store energy and further reduce the cost of buying electricity. This will lead to a decrease in demand for energy generated by nonrenewable energy companies and, as a consequence, a decrease in revenues in the conventional energy production market.

The long-term change model in this article allows us to determine that the difference in energy consumption by utilities at a low value of the green tariff and a high value will be no more than $5 \%$. Because of this, a scenario of critical changes in the renewable and non-renewable energy sectors is unlikely. However, the rate of adoption of renewable energy to reduce emissions from nonrenewable sources would be reduced. The model provides data that with a high value of the green tariff, the rate of adoption of photovoltaic modules will increase to $30 \%$, with an average of $27 \%$, and with a low of $23 \%$. Reduced growth of PV generation could jeopardize renewable energy projects.

\subsubsection{Denmark}

The colossal experience of Denmark in the development and use of renewable sources is described by the authors in the article [9]. The authors cite data that already in 1990 the country had several thousand wind power guilds. The country's main renewable energy model is the active participation of the local population as owners of energy generating systems. In 2001, 150,000 small farms acted as owners of shares in wind projects. The introduction of a carbon tax in 1992, as well as increases in energy taxes, spurred the development of renewable energy. By 2015, more than half of the country's electricity was generated by renewable sources, $40 \%$ of which was provided by wind systems. Offshore wind turbines provided a large share in wind energy, accounting for $40 \%$ of all wind generation. Thanks to the power sector design model, $50 \%$ of the total electricity market was for small private power generation systems.

The authors of this article note that the green tariff in Denmark was introduced in 1993 as a tool to regulate development. Together with a favorable tax system for RES, tax deduction on interest on loans for the purchase of shares of a wind turbine, the green tariff was able to influence the speed of development of RES. As a result of these incentives, by $2002,15 \%$ of all generated energy in the country was provided by wind systems. In addition, taxes on income from shares of the generating systems were not levied to a certain level, which reinforced the achieved success. In the article [10], the authors cite data that in 2001 the Danish government abandoned the green tariff for wind power generation systems. The final rate was $€ 0.058 / \mathrm{kWh}$. The country's government has chosen the RPS system with marketed green certificates due to its wider range of applications. However, as a result of the abandonment of the green tariff, the development of the wind energy sector underwent stagnation over the next 7 years. The green tariff continued to be used for biogas, solar energy, wave and tidal energy. For new installations in the period of 10 years, the tariff rate was $0.08 € / \mathrm{kWh}$, then the price is reduced to $0.054 € / \mathrm{kWh}$. The authors note that a photovoltaic boom was recorded in Denmark in 2012. As a result of the development of supply on the market of photovoltaic systems, as well as the worldwide decline in prices for this technology, 70,221 solar systems were put into operation in 2012, this is equivalent to 406 MW, $73 \%$ of the total capacity of the country's solar systems were installations with a capacity of less than 6 $\mathrm{kW}$. For 2014, their production is estimated at $597 \mathrm{GWh}$.

The authors also report that by 2024 the capacity of solar installations will reach a capacity of 1,140 MW. Denmark's success is underpinned not only by its favorable development environment, but also by its pricing and taxation policies. In 2014, the price of electricity in Denmark was the highest in Europe - 0.3042 euro / $\mathrm{kWh}$, tax revenues amounted to 0.173 euro cent / $\mathrm{kWh}(56.84 \%$ of the price), so the country's government had the financial ability to stimulate and subsidize the RES industries.

\subsubsection{Spain}

Regarding the issue of renewable energy in Spain, this information is provided in the article [11]. With its successful renewable energy incentive policy, Spain has one of the highest installed wind power capacity in the world. The authors cite data that in $2016,45 \%$ of the installed electric capacity, as well as $39 \%$ of the total electricity production, were provided by renewable sources. Since 2007, the installed capacity of PV and wind systems has grown by $70 \%$, resulting in a $43.1 \%$ reduction in carbon dioxide $\left(\mathrm{CO}^{2}\right)$ emissions in 2016 compared to 2007 and $18.3 \%$ compared to 2015 , and amounted to 63.5 million tons of $\mathrm{CO}^{2}$.

As incentives for the development of environmentally friendly energy, the Spanish government uses three types of support mechanisms, namely: green tariff, green premiums and payment for the capacity spent on electricity generation. Green awards are a mechanism to support renewable energy companies through financial incentives. The amount of the payment varies depending on the price at which the manufacturer sells the electricity. The closer the price to the market price, the higher the size of the incentive paid by the state. Green premiums turned out to be an effective incentive and allowed not only to increase the emergence of new manufacturers, but also to induce existing production to update prices based on the market situation. However, due to the increased demand for this support mechanism, the Spanish government had to cancel the possibility of receiving payments from new producers from 2013, since the subsequent tariff deficit could destabilize the country's energy market.

The article also notes that due to the unsustainable nature of renewable energy supply, the national government has identified incentives for the development of flexible energy producers as the most preferable. Flexible energy producers are companies capable of producing energy from both renewable and nonrenewable sources. The most preferred incentive for these 
companies is to pay for the capacity used to generate electricity, since it provides the greatest predictability in the long term of use.

\subsection{South America (CELAC countries)}

According to the information in the article [12] "Green energy" has not bypassed Latin America along with the Caribbean region. As of 2010, 12 countries from the Community of Latin America (Brazil, Chile, Argentina, Colombia, Costa Rica, Ecuador, Jamaica, Mexico, Ecuador, Saint Lucia, Saint Vincent and the Grenadines, Uruguay) and the Caribbean (CELAC) completed all tasks for the implementation and operation of systems powered by RES. Referring to [13] in Latin America, renewables (excluding hydropower) accounted for $2.5 \%$ of total electricity generation in 1995, 6.42\% in 2014 and $11 \%$ in 2018 . The region currently benefits from one of the greenest energy pools in the world, thanks to a strong hydropower base and a growing share of solar and wind energy. And this is indeed the case when hydropower is included (this share is about 58\% in Latin America compared to $36 \%$ in Europe and $25 \%$ on average in the rest of the world). As for subsidies from the state under the FIT scheme, it is applied in Bolivia, Ecuador, the Dominican Republic and Honduras. There are also countries in this region that have had a negative experience of use. For example, in Argentina and Brazil in the period 1998-2006, this policy did not contribute to practically any development of the renewable energy complex, which was influenced by unfavorable macroeconomic conditions at that time period. Six countries - Colombia, Venezuela, Paraguay, Costa Rica, Jamaica, and Belize - have no economic or regulatory support policies, while Mexico, Guatemala, El Salvador, and Panama only offer tax breaks.

However, there are other types of stimulation of the development of the renewable energy complex, for example, in countries such as Argentina, Brazil, Uruguay, Peru and Nicaragua, since the beginning of the 2nd decade of the 21st century, the system of "auctions" has been actively used. The system of auctions allows the state to distribute quotas in its country for the construction of new power generation capacities using RES. It is assumed that the land plot, the estimated cost of connection, all the necessary permits for construction will be put up for auction, as well as all the necessary deductions (for example, land rent, etc.) to local budgets will be determined. The winner of the auction (companies engaged in generation based on RES) will be the company that offers the minimum price for the sale of electricity, and in Peru, it has been actively used since the same years reverse auction (a more detailed description of reverse auctions is described in the section "Australia") system [14 pp. 559].

The auction system has several advantages that explain its introduction in South America. First, the system provides a stable and well-known revenue stream after project awards, making it easier for the government to fund projects. Secondly, Auctions help to stimulate competition between manufacturers. Thirdly, in addition to costs, auctions allow the introduction of other selection criteria (e.g., job creation) among the tenders submitted in accordance with public policy goals. Finally, the auction scheme fits well into the institutional structure of the electricity system of most Latin American countries.

However, the disadvantage of auctions is that they facilitate entry into the markets of "large" existing players, which makes it difficult for new and smaller producers to enter. Thus, this tool should be complemented by specific policies in a number of countries focused on small and decentralized renewable energy projects.

\subsection{North America}

\subsubsection{Canada}

Ontario's energy experience and the very unfavourable conditions for the active development of RES through the use of FIT is described in [14, pp. 507]. The authors write that in 2017, the volume of energy production for the year was $144.3 \mathrm{TWh}$, and this is $10.6 \mathrm{MWh}$ per capita. Nuclear power sources accounted for $63 \%$ of the energy generated, while hydroelectric systems accounted for $26 \%$ (medium and large dams). The FIT was first introduced by the Ontario government in 2009. Its goal was to stimulate the development of non-hydro-renewable energy sources. As a result, by 2017 , energy production from RES increased from $1.5 \%(0.9 \%$ - wind, $0.6 \%$ biofuels and solar energy) to $7 \%$. Wind energy accounts for $6 \%$ or $84 \%$ of the total renewable energy. Nevertheless, the author points out that the total amount of energy produced by non-hydro-renewable sources still accounts for $0.5 \%$ of the total amount of energy produced. It also describes the main reasons why there was no major success in using the FIT as an incentive for the development of RES.

In December 2016, the microFIT and FIT programs were discontinued, followed by a return to the tendering system. For nuclear power, the system of tenders is considered as the most expedient due to the increased competitiveness in the local market. An additional FIT for solar systems in the form of a discount program for households for the purchase of energy from photovoltaic installations was supposed to be introduced in 2018, but due to the change of the majority in the government from a liberal to a conservative party, the program was canceled. In September 2017, 50\% of the shares of the state-owned Ontario transmission company (Hydro One) were sold to private investors, as a result of which the direction of the energy sector changed the direction of activity from the goals set by the government to corporate goals, focusing on the profitability of development projects.

The 2015 Ontario Climate Change Strategy pledges to cut 1990 emissions by $15 \%$ by $2020,37 \%$ by 2030 , and $80 \%$ by 2050 . This strategy is based on dependence on nuclear energy with the subsequent development of infrastructure and ensuring a high price attractiveness of the cost of energy for the population. These events allowed the author of the book to notice that the energy 
sector has moved from a policy of stimulating the development of decentralized energy production through RES, to large-scale centralized energy production through nuclear power plants.

As a consequence of the bias of energy policy towards corporate goals, RES remain in the background and do not play a visible role in energy generation. Corporate dominance in the energy industry is also shifting the way energy production is developed in general. In the article [15], the authors provide evidence of the reasons for the government, which served to choose the vector of energy development. The key idea was that the government of the country cannot impose mandatory conditions for energy consumption on companies and municipalities. The struggle of the state for the development of renewable sources incurs losses for companies, increases in taxation to maintain the efficiency of the FIT. The fact that the burden of stimulating RES ultimately falls on the taxpayer served as a sufficient argument for the development of a solution for the transition to the path of centralized energy development.

For 2018 in Ontario, $72 \%$ of all contracts for FIT (4.8 GW) were distributed among corporate projects, $24 \%$ $(1,171.3 \mathrm{MW})$ among projects with full or joint ownership of the local population, 4\% (201.6 MW) among projects with full or jointly owned by the community. From 2009 to 2017 , more than $230 \mathrm{MW}$ of solar energy was purchased for residential buildings with an installed capacity of no more than $10 \mathrm{~kW}$ in approximately 26,000 houses.

The author of the aforementioned book emphasizes that the fastest growing model for the production of renewable energy are systems owned by the population. According to this model, for March 2018, contracts were concluded at a FIT for 1,171.3 MW. 827.3 MW were provided by wind power systems, 270.5 MW by photovoltaic systems, 74.4 MW by hydropower systems, $0.5 \mathrm{MW}$ by bioenergy systems. As the main reason for the growth of renewable energy sources, the author indicates the presence of proactive people who are interested in the use of environmentally friendly energy technology. The interest is provided by the presence on the local market of many technical solutions at an adequate price, as well as a developed intellectual and technical base for the operation and construction of RES. The availability of the required FIT rate to ensure the minimum profitability of energy systems reinforces the desire of people to take the initiative in the field of green energy or to reduce the cost of purchasing energy through self-sufficiency. It is noted in [14, pp. 507] that changing the vector of energy development will require lengthy discussions and global changes in the energy sector of the country as a whole.

\subsubsection{United States of America (USA)}

The experience in the development of environmentally friendly energy is mentioned in the article [16], and the authors of the article also emphasize that the United States does not have a unified policy to stimulate the development of renewable energy sources, each state that takes an active participation in the development of green energy on its territory, establishes its own unique methods of encouragement and their size.

Richard Schmalensee in his article [17] details the methods of stimulating development used in various states of America for photovoltaic systems. The main method of promoting solar energy across the country is through income tax incentives. As a consequence of the lack of large revenues for solar producers, they need a profitable partner, such as a large bank, to realize tax breaks. Such mutually beneficial cooperation allows obtaining rather significant support of generating companies from the country's commercial sector. FIT with fixed capacity per $\mathrm{kWh}$ and Renewable Energy Portfolio Standards (RPS) are applied in 29 US states and the District of Columbia. The main logic behind their use is to encourage energy generation. The state of Massachusetts has one of the lowest rates of solar energy received due to its geolocation, but thanks to the unique policy of the regional government to introduce into the RPS portfolio the obligation of distribution companies to meet their RES needs by using only state-owned generators, the state ranked fourth nationally in the number of installed solar system capacity in 2013. The author of this article notes that the generation of photovoltaic energy in residential buildings in the United States has a number of advantages over other types of generation, since the amount of benefits increases and is calculated taking into account the increased price of the system per unit of power compared to utility systems, the inability to optimally orient the roof of a residential structure, resulting in reduced electricity generation, as well as the fact of net energy accounting, in which household solar generation receives retail prices, as opposed to utility generating systems, which receive wholesale prices. However, the general trend in the development of solar energy generation systems in the country has a clear preference for large-scale, rather than private electricity production.

The California government's valuable renewable energy experience is described in [14, pp. 479]. The RPS, created back in 2002, is rated by the government as the most ambitious in the United States and obliges grid companies to purchase up to $33 \%$ of the total supply from renewable sources. In 2015, the "Senate Bill 350" or "Clean Energy and Pollution Act" was passed, which meant increasing the amount of energy required for companies to purchase from RES from $33 \%$ to $50 \%$ by 2030.

The authors of the aforementioned book note that the understanding of the US government to reduce the use of fossil energy, the ambition to reduce the use of fossil energy by $100 \%$ renewable electricity by 2050 , would allow the state to take among the leading positions in the development of renewable energy not only within the United States, but also in other countries.

In 2016, California has 268 green energy incentive programs. One of the successful incentives by the authors of the book "Adjusting Tariff" is to support generators with a capacity of less than $3 \mathrm{MW}$. The Government has set the required energy generation output at $750 \mathrm{MW}$ under this program. The contract for the adjustment tariff was awarded to a green energy generating company that 
could create a profitable generation project within the price set by the investor-owned utility company (IOU). However, this program has not gained widespread acceptance and is criticized as too complex a reward system. The closure of the last nuclear power plants by 2025 , and increased weather conditions are supporting the government to create a decentralized energy system capable of sustainable performance during peak load hours.

In the residential sector of California, solar energy takes the leading comparison in comparison with other RES. 550,000 consumers using photovoltaic systems for clean energy metering were recorded from 2007 to 2017. In November 2017, solar installations with a total capacity of $5900 \mathrm{MW}$ were registered.

\subsection{Australia}

The data presented in article [18] describe in great detail the consequences of the excessive development of the use of fossil resources for electricity generation, as well as the priority goals of the Australian Capital Territory government to reduce global emissions through the transition to RES, because in 2014 greenhouse gas emissions by per capita were 3.1 times higher than the average emissions in the European Union, and 4 times higher than the world average. In 2017, greenhouse gas emissions from electricity generation accounted for $35 \%$ of total emissions across the country.

Australia's energy supply has historically relied on the country's significant fossil fuel reserves. In the period 2015-2016. electricity production in the country was provided by the system using black and brown coal - 63\%, as well as using natural gas $-22 \%$. However, the location of the Australian continent provides the largest amount of solar radiation received per unit area, and Australia also has one of the best wind resources. In 1965, the peak in renewable energy production was reached at $23 \%$, but due to the excessive use of fossil resources, the figure fell to $9 \%$ by 2000 . The policy of developing renewable energy sources using the FIT allowed the indicator to recover to $14.8 \%$, but this figure is significantly lower than the peak value in 1965 .

The referenced article explores the Australian government's use of additional renewable energy incentives such as reverse FIT auctions. A reverse FIT auction is a real-time battle between renewable energy producers for a contract for the supply of a certain amount of electricity, in which the producers offer a price according to which they are ready to provide energy to the customer. The main purpose of reverse auctions in Australia is the controlled distribution of renewable energy demand. Excessive subsidies for the development of green energy production at the expense of a high FIT rate carries with it the risk of violation of parity between companies operating with renewable energy and traditional energy, and subsequently losses of companies with non-renewable sources. Reverse auctions are viewed as a regulator of development and a solution to this problem.

Between 2012 and 2016, the first reverse auctions were held for the right to receive FITs for $640 \mathrm{MW}$ of solar and wind generating systems. The success of these auctions became the basis for the wider use of this system. The Queensland government initiated a reverse auction for $400 \mathrm{MW}$ in 2017, and the Victoria government initiated for $650 \mathrm{MW}$ of renewable electricity. In 2017, all but 2 of Australia's 8 states and territories committed to achieving zero net emissions by 2050. The Australian government needs to achieve a target of $50 \%$ of electricity generated from RES by 2030 to have a proportionate impact on the level of global warming containment. This indicator is based on the country's obligations under the United Nations Convention on Climate Change and is not an easy task for the country. To achieve the required values, the Australian government needs to increase the production of environmentally friendly energy by 3 times. Reverse auctions for FIT should take on a major role in stimulating the development of renewable energy in the regions of Australia.

There are also small renewable energy sources ready to be developed across the country. Data describing recommended FIT rates for small 3 to $5 \mathrm{~kW}$ installations used in Victorian homes are given in [19]. Stimulating the development of photovoltaic systems in the residential sector receives the greatest response when using the FIT. The authors of the article made a calculation, as well as surveys, according to which the most desirable range of the tariff rate from the point of view of an individual investor was from 20.29 AUD cents / $\mathrm{kWh}$ to 28.25 AUD cents / $\mathrm{kWh}$. From the point of view of retailers, the satisfactory rate is in the range of 15.99 AUD cents / $\mathrm{kWh}$ to 20.29 AUD cents / $\mathrm{kWh}$. For consumers, the acceptable range of the FIT rate was from 11.96 AUD cents / $\mathrm{kWh}$ to 15.99 AUD cents / kWh.

\subsection{Africa}

African countries have a huge potential for the development of RES due to their geographical location and climatic conditions. Many experts build models of renewable energy systems in Africa, which demonstrate the highest performance indicators relative to renewable energy systems in other countries. The [20] provides data on the high prospects for the development of wind energy, as well as the main obstacles that impede the development of RES in general. Theses such as the lack of a legislative framework, low development of infrastructure for the transportation and distribution of energy, high prices for components of energy systems in the domestic market are given by the authors of the article and are used as a justification for the extremely low rate of introduction of RES in the energy sector of African countries.

Methods for stimulating the development of renewable energy in Africa are described as an example in the two countries below.

\subsubsection{Egypt}

A study in the article [21] describes a problem in calculating the profitability of using small wind turbines with a capacity of less than $200 \mathrm{~kW}$. Due to the low green 
tariff rates and its low development, the development of renewable energy sources in Egypt is at an early stage and requires adaptation to current indicators of both consumption and energy production technologies.

\subsubsection{Tanzania}

Tanzania's underdeveloped energy sector prompts the country's government to find ways to stimulate the development of electricity producers. A large number of settlements outside the state power grid are forced to use diesel generators to meet their energy needs. A possible solution to this problem by using the green tariff as the main tool for attracting investment in the development of RES is described in [22]. The authors note that the use of diesel generators entails an increased price of electricity due to the high cost of the production system. The comparative analysis carried out in the article demonstrates that renewable energy production systems are significantly cheaper in terms of cost and are able to attract not only local investment, but also large European organizations for the development of renewable energy sources.

Renewable electrification of rural areas can be solved according to the model given by the authors. The current green tariff rate for PV installations is US $\$ 0.24 / \mathrm{kWh}$. This indicator is estimated in the model as the minimum for ensuring the non-profitability of small hydroelectric power plants, but too low for photovoltaic systems. The required markup to the green tariff rate should be US \$ $0.11 / \mathrm{kWh}$ to ensure the required profitability of the systems preferred in Tanzania. The geographic location of the country is capable of providing high rates of solar power generation. The government spends about US \$ 36 million to subsidize diesel energy production (with a loss of US $\$ 0.42$ for each $\mathrm{kWh}$ produced), according to the authors' model, the required subsidies for a rate increase should be US \$ 31.5 million, which in its own turn will create a long-term basis for the existence and development of RES in the country.

Unlike developed countries, the Tanzanian government considers the green tariff not only as an incentive for the development of renewable energy sources with a subsequent reduction in harmful emissions from traditional energy, but also as a possible basis for the systematic electrification of zones not connected to the power grid with a subsequent improvement in the quality of life of the population.

\section{Russia}

In the previous chapter, the experience of foreign countries in stimulating the development of renewable energy on behalf of government agencies was considered, one of such incentives is the "Green Tariff" system. Unfortunately, on the territory of the Russian Federation in matters of renewable energy, until mid-2017, active support from the state was not considered, however, from July 19 of the same year, the first steps in this direction appeared, for example, a description of the Russian legal framework for renewable energy sources, as well as the system stimulation of their development is described in [23].

The main disadvantages of the draft law described are the problems of the complexity of connecting various entities to the power grids in general, the lack of logistics in the existing network both for receiving generated energy from micro-generation facilities and for its further transportation, which greatly affect the complexity of implementation and profitability of projects for the construction of small renewable energy sources. The lack of a well-developed balanced legal relationship between electricity producers and consumers in the project creates additional difficulties. The rights of consumers, as well as the protection of their legitimate interests, are derived from the rights of energy companies, which in general negatively affects the interest of third parties in the development of the country's green energy sector.

In [23], also provide a recommendatory model of changes in the draft law to increase the attractiveness of the RES sector, as well as to create a reasonable profitability of micro-generation projects at the design stage. The installed capacity of small renewable energy sources should be increased from 15 to $25 \mathrm{~kW}$, this will allow the use of generating systems in areas remote from the network and provide household needs in modern residential buildings. The change should also affect the basic definition of a microgeneration object. The requirement that the total capacity of the generating system should not exceed the total capacity of the consumer's energy receiving devices should be abolished, and a definition should be introduced that the producer cannot only use energy for personal needs, but can also sell the surplus. The specified model of changes is assessed in the article as the required minimum to create a favorable environment for the existence and development of renewable energy sources in Russia. Nevertheless, in 2019, dated December 7, the aforementioned draft was finalized, signed and adopted as a federal law [24]. This law introduces such a concept as a "microgeneration object." Again, as already indicated in the above article, the maximum power of microgeneration facilities in the Russian Federation cannot exceed $15 \mathrm{~kW}$.

Referring to this federal law, the object of microgeneration can be called objects for the generation of electric energy, which are owned by the right of ownership or other legal basis to a consumer in the form of a private person or various organizations). Both renewable energy sources (solar panels, wind generators, tidal / wave power plants, etc.) and traditional energy facilities (for example, internal combustion generators) have the right to act as a source of generation. And also all possible combinations of them. The connection of such systems to the general power grid should be at a level not higher than $1 \mathrm{kV}$. It should also be taken into account in this case that the generation of electricity into the general network should not take into account electrical equipment designed to serve more than one room in the building.

The law also establishes a base rate for the cost of electricity generated at micro-generation facilities and obliges the guaranteeing supplier to purchase this electricity at prices that do not exceed prices on the 
wholesale market at which the guaranteeing suppliers purchase electricity and capacity. In addition, the law excludes activities for micro-generation of electricity from types of entrepreneurial activities, thereby exempting individuals from tax collections. faces.

Since autumn 2020, there has been a practice of implementing the law on distributed microgeneration (FIT).

If a citizen of the Russian Federation has his own source of electricity generation up to $15 \mathrm{~kW}$ at his disposal, then as an individual he must contact the local energy sales company, write an application for obtaining a technical specification indicating the generating capacity of the facility.

Further, the citizen needs to purchase and supply a specialized meter that allows you to measure and transfer data and the performance of the connected system. The next stage is the registration of a micro-generating facility on the Internet site for the publication of an up-to-date summary of data on the performance of the system, its public recognition as a source of energy generation, as well as the possibility of concluding transactions for the purchase of generated energy by other participants of this platform.

Since companies buy, electricity from power grid suppliers at tariffs higher than those set by individuals. to persons, they have an interest in purchasing electricity generated into the grid by citizens using the "green tariff" system at the above site, since the rate for the tariff is lower than the rate of the energy sales company. In this case, the "green tariff" system stimulates both legal entities and individuals faces.

The main problem of this practice was the power supply companies that were reluctant or even refused to conclude contracts with such citizens. For this reason, on March 2, 2021, the government adopted Resolution No. 299 [25]. According to this regulation, power supply companies must conclude an appropriate contract for the purchase of electricity from a person who has a renewable generation source on its territory. Owners of any territories, except for apartment buildings, can participate.

All of the aforementioned amendments to the draft law have a positive impact on the development of renewable energy in Russia, however, we are talking only about minor support, since these measures are not enough to increase its development prospects. It is necessary to make additional amendments to the bill, allowing to give additional incentives to citizens who are interested in distributed microgeneration, since at the moment, to install systems with a capacity of $1 \mathrm{~kW}$, an average of about $\$ 1300$ must be invested (we are talking about a system of solar panels, as the cheapest option), which makes profitability a big question. This support will allow:

- Return to the participants of the program a certain part of the funds or allocate subsidies for the purchase and installation of their generating systems.

- Purchase equipment at a special reduced interest rate if purchased on credit.
- Set a guaranteed (fixed) tariff for such systems, as well as oblige utility companies to make long-term commitments and contracts.

\section{Conclusion}

Renewable energy is seen by the global community as an indispensable key to reducing greenhouse gas emissions. The actively developing industry demands more energy every year, and the uncontrolled increase in the capacity of traditional energy systems leads to catastrophic consequences for the ecology of the planet. This article examines the experience of countries around the world in the use of various incentives for the development of renewable energy sources.

Based on the data obtained, we can conclude that the most successful system of stimulating the development of environmentally safe energy is the creation of economic attractiveness of green energy generation systems. Systems such as RSP, FIT, auctions, reverse auctions, as well as various tax incentives have proven to be workable incentives and made it possible to achieve the required values of the generated energy in developed countries (Japan, USA, Australia, Germany, Great Britain, Denmark, China, South Korea) according to the ambitions of the leadership of each country, at the expense of renewable energy sources to reduce emissions of environmentally harmful gases into the atmosphere.

Moreover, the article examines various projects of countries with little support for renewable energy or countries that are taking the first steps in this direction (CELAC countries, Egypt, Canada Tanzania, Saudi Arabia and Russia) using the above-mentioned incentives. These examples of countries indicate that in most cases the main incentive for active participation in the development of green energy is not a desire to care about the environment, but the economic attractiveness of renewable energy systems.

Of course, each system of development incentives has its unique disadvantages and advantages, they have also been considered in the existing systems in different countries.

The active participation of governments in the regulation and modernization of incentive systems allows countries taking the initial steps to avoid major mistakes, as well as to attract new participants in the fight against global warming.

\section{Further research}

Further research will be aimed at analyzing the economic efficiency of the functioning of integrated photovoltaic systems for the conditions of Russia, taking into account the current legislation. 
The research was carried out under State Assignment Project [no. FWEU-2021-0002 (AAAA-A21121012090012-1) of the Fundamental Research Program of Russian Federation 2021-2030. The authors would like to thank anonymous reviewers for their valuable comments.

\section{References}

1. Dong Yanli, Shimada Koji. (2017) "Evolution from the renewable portfolio standards to feed-in tariff for the deployment of renewable energy in Japan" Renewable Energy 107: 590-596.

2. Xia, Fang, Lu, Xi, Song, Feng. (2019) "The role of feed-in tariff in the curtailment of wind power in China" Energy Economics, 104661.

3. Yawen Zhao, Hui Hong, Hongguang Jin. (2016) "Appropriate feed-in tariff of solar-coal hybrid power plant for China's Inner Mongolia Region" Applied Thermal Engineering 108: 378-387.

4. Tae-hyeong Kwon. (2020) "Policy mix of renewable portfolio standards, feed-in tariffs, and auctions in South Korea: Are three better than one?" Utilities Policy 64: 101056.

5. Khalid Alrashoud, Koji Tokimatsu. (2020) "An exploratory study of the public's views on residential solar photovoltaic systems in oil-rich Saudi Arabia" Environmental Development 35: 100526.

6. Wonsuk Ko, Essam Al-Ammar, Mohammad Almahmeed. (2019) "Development of Feed-in Tariff for PV in the Kingdom of Saudi Arabia" Energies 12(15): 2898.

7. Claudia Hitaj, Andreas Löschel. (2019) “The impact of a feed-in tariff on wind power development in Germany" Resource and Energy Economics 57: 18-35.

8. Monica Castaneda, Sebastian Zapata, Judith Cherni, Andres J. Aristizabal, Isaac Dyner. (2020) “The long-term effects of cautious feed-in tariff reductions on photovoltaic generation in the UK residential sector" Renewable Energy 155: 1432-1443.

9. Curtin Joseph, McInerney Celine, Johannsdottir Lara. (2018) "How can financial incentives promote local ownership of onshore wind and solar projects? Case study evidence from Germany, Denmark, the UK and Ontario" Local Economy 33(1): 40-62.

10. Andri Pyrgou, Angeliki Kylili, Paris A.Fokaides. (2016) "The future of the Feed-in Tariff (FiT) scheme in Europe: The case of photovoltaics" Energy Policy 95: 94102.

11. António Cardoso Marques, José Alberto Fuinhasb, Daniela Pereira Macedo. (2019) "The impact of feed-in and capacity policies on electricity generation from renewable energy sources in Spain" Utilities Policy 56: 159-168.

12. David Jacobs, Natacha Marzolf, Juan Roberto Paredes, Wilson Rickerson, Hilary Flynn, Christina Becker-Birck, Mauricio Solano-Peralta. (2013) “Analysis of renewable energy incentives in the Latin America and Caribbean region: The feed-in tariff case" Energy Policy 60: 601-610.

13. Germán Bersalli, PhilippeMenanteau, Jonathan ElMethni. (2020) "Renewable energy policy effectiveness: A panel data analysis across Europe and Latin America" Renewable and Sustainable Energy Reviews 133: 110351.

14. Jens Lowitzsch (ed). Energy Transition Financing Consumer Co-Ownership in Renewables. Springer, 2019, $-794 \mathrm{p}$.

15. Alan Whiteley, Anne Dumbrille, John Hirsch. (2021) "Access to Justice: Recommended Reforms to the Ontario Justice System Using the Green Energy Act as an Example” Open Journal of Social Sciences 9: 1-19.

16. Elbert Dijkgraaf, Tom P. van Dorp, Emiel Maasland (2018) "On the Effectiveness of Feed-in Tariffs in the Development of Solar Photovoltaics" The Energy Journal 39: 81-99

17. Richard Schmalensee. (2015) "The future of solar energy: A personal assessment" Energy Economics 52: 142-148.

18. Greg Buckman, Jon Sibley, Megan Ward. (2019) “The large-scale feed-in tariff reverse auction scheme in the Australian Capital Territory 2012, to 2016" Renewable Energy 132: 176-185.

19. Hong Xian Li, Yitao Zhang, Yan Li, Jiaxin Huang, Glenn Costin, Peng Zhang. (2021) "Exploring paybackyear based feed-in tariff mechanisms in Australia" Energy Policy 150: 112133.

20. Akintomide Afolayan, Akinsanola, Kehinde O Ogunjobi at el (2021). "Projected changes in wind speed and wind energy potential over West Africa in CMIP6 models" Environ. Res. Lett. 16: 044033

21. Suzan Abdelhady, Domenico Borello, Simone Santori. (2015) "Economic feasibility of small wind turbines for domestic consumers in Egypt based on the new Feed-in Tariff' Energy Procedia 75: 664-670.

22. M.Moner-Girona, R.Ghanadan, M.Solano-Peralta, I.Kougias, K.Bódis, T.Huld, S.Szabó. (2016) “Adaptation of Feed-in Tariff for remote mini-grids: Tanzania as an illustrative case" Energy Procedia 53: 306-318.

23. Kamy'shanskiy Vladimir P (2018) "Civil law promotion of energy saving using renewable sources of energy as a form of energy saving" Civil Law 4: 8-11.

24. Federal Law "On Amendments to the Federal Law" On Electric Power Industry "in terms of the development of microgeneration.Available at:http://www.consultant.ru/document/cons_doc_LAW_ 341801/.

25. Resolution of the Government of the Russian Federation of $03 / 02 / 2021$ N 299. Available at:http://www.consultant.ru/document/cons_doc_LAW_ $378535 /$. 